\title{
“PENGARUH NPL DAN BOPO TERHADAP ROA PADA PERBANKAN YANG TERDAFTAR DI BURSA EFEK INDONESIA 2013-2017
}

\author{
${ }^{1}$ Vivian Arni Yunita1, ${ }^{2}$ Lukmanul Hakim2, ${ }^{3}$ putri Reno Kemala Sari3 \\ ${ }^{1 *}$ Fakultas Ekonomi dan Bisnis Universitas Teknologi Sumbawa \\ ${ }^{2}$ Dosen Fakultas Ekonomi dan Bisnis Universitas Teknologi Sumbawa \\ ${ }^{3}$ Dosen Fakultas Ekonomi dan Bisnis Universitas Teknologi Sumbawa \\ email: vivianyunita22@gmail.com
}

\begin{tabular}{|c|c|}
\hline & Abstrak \\
\hline $\begin{array}{l}\text { Diterima } \\
\text { Bulan Juli } 2019\end{array}$ & $\begin{array}{l}\text { Penelitian ini bertujuan untuk mengatahui pengaruh } n p l \text { dan bopo terhadap roa pada } \\
\text { perbankan yang terdaftar di bursa efek Indonesia 2013-2017,. Penelitian ini } \\
\text { menggunakan metode kuantitatif kausal. Sampel dalam penelitian berjumlah } 20\end{array}$ \\
\hline Diterbitkan & perbankan yang diperoleh dengan metode purposive sampling. Data yang diperoleh \\
\hline Bulan Juli 2019 & $\begin{array}{l}\text { dianalisis dengan menggunakan eviews } 9 \text {. Hasil analisis dalam penelitian ini } \\
\text { menunjukkan bahwa (1) secara parsial NPL tidak berpengaruh signifikan dan }\end{array}$ \\
\hline Keyword: & mempunyai efek negatif terhadap $R O A$, (2) secara parsial BOPO berpengaruh negative \\
\hline $\begin{array}{l}\text { NPL, BOPO, } \\
\text { ROA. }\end{array}$ & $\begin{array}{l}\text { signfikan terhadap } R O A \text {, (3) secara bersama-sama } N P L \text { dan } B O P O \text { berpengaruh } \\
\text { terhadap } R O A \text { pada perbankan yang terdaftar di bursa efek Indonesia 2013-2017, }\end{array}$ \\
\hline
\end{tabular}

\section{PENDAHULUAN}

Di era globalisasi saat ini, perbankan merupakan suatu lembaga atau sektor perekonomian yang memegang peranan penting dalam pertumbuhan ekonomi. Seperti yang kita ketahui bank merupakan badan usaha yang menghimpun dana dari masyarakat dalam bentuk simpanan, menyalurkan kredit dan bentuk lainnya dalam rangka meningkatkan taraf hidup rakyat banyak (Kasmir, 2012). Untuk kita ketahui industri perbankan dalam menjalankan kegiatannya juga terdapat berbagai risiko, diantaranya dalam pemberian kredit dimana dalam penelitian ini lebih memfokuskan ke kredit macet atau sering disebut dengan Non Performing Loan (NPL).

Menurut Ikatan Bankir Indonesia, (IBI, 2015) NPL adalah risiko akibat kegagalan debitur atau pihak lain dalam memenuhi kewajiban melunasi kredit pada bank. Pada tahun 1997-1998 terjadi krisis ekonomi yang luar biasa yang disebabkan oleh faktor internal dan ekternal, faktor ekternal pada saat itu di pengaruhi oleh mata uang Asia berguguran sampai dengan nilai rupiah yang sangat lemah. Sedangkan faktor internal dipengaruhi oleh sektor keuangan yang begitu bebas sehingga dana asing mengalir deras ke perbankan dan pasar modal, pemerintah melepas nilai tukar sesuai dengan harga pasar serta nilai rupiah yang semakin melemah membuat investor asing kehilangan kepercayaan serta meninggalkan Indonesia. Sehingga perusahan-perusahaan besar yang saat itu melakukan ekpansi bermodal utang dari luar negeri diminta untuk membayar utang JURNAL MANAJEMENDANBISNIS yang membengkak dikarenakan rupiah melemah (Kasmir, 2014).

Pada saat itu perbankan banyak yang mengalami kredit macet oleh karena itu dikeluarkan Peraturan Bank Indonesia (PBI) No.17/11/2015, menetapkan bahwa rasio $N P L$ maksimal 5\% dari total kredit. Pelaturan tersebut dibuat agar dapat mengawasi serta mengatur lalu lintas perekonomian agar tidak terjadi krisis moneter. Selain meminimalkan rasio NPL perbankan juga harus dapat mengefesienkan biaya yang dikeluarkan, salah satu cara untuk mengukur operasional perbankan dengan cara menilai beban operasional terhadap pendapatan operasional.

Menurut (IBI, 2015) beban operasional terhadap pendapatan operasional merupakan suatu risiko yang dapat menimbulkan kerugian yang salah satunya merupakan kerugian potensial berupa kehilangan kesempatan untuk memperoleh keuntungan. Pada dasarnya resiko Menurut Edaran Bank Indonesia No.13/24/DPNP/2011, nilai maksimal dari BOPO 94\% jika nilai BOPO lebih dari ketentuan maka bank tersebut masuk kedalam kategori tidak efesien. Untuk itu bank harus dapat mengefesiensikan biaya yang dikeluarkan agar dapat memperoleh profitabilitas yang maksimal salah satunya dengan melihat nilai $R O A$.

Profitabilitas menggambarkan ukuran tingkat efesien manajemen suatu perusahaan.Peraturan BI No.13/PBI/2011 tentang penilai tingkat kesehatan Bank Umum menunjukkan bahwa

Hubungan dari kedua rasio ini dapat 
mempengaruhi profitabilitas perusahaan tingginya rasio $N P L$ dapat menurunkan pendapatan perbankan dalam mengembalikan dana yang telah diberikan kepada debitur, begitu juga dengan tingginya rasio BOPO menunjukkan tidak efesienya perbankan dalam menjalankan operasional sehingga dapat menyebabkan kerugian bagi bank.

\section{LANDASAN TEORI}

\section{Non Perfoming Loan (NPL)}

NPL berakibatkan pada kerugian karena tidak diterimanya kembali dana yang telah disalurkan maupun pendapatan bunga sehingga terjadinya penurunan pendapatan secara total (Ismail, 2014). Kesehatan bank menjadi kepentingan bagi semua pihak diantaranya, pemilik bank, manajemen bank, masyarakat sebagai pengguna jasa dan pemerintah sebagai regulator. Sebagaimana yang kita ketahui peran OJK didalam mengawasi jalannya transaksi keuangan yaitu memberikan rasa aman atas investasi serta transaksi yang dilakukan melalui lembaga keuangan.

\section{Beban Operasional Terhadap Pendapatan Operasional (BOPO)}

Beban operasional terhadap pendapatan operasional merupakan suatu risiko operasional ini dialami oleh keseluruhan bank. Biaya operasional merupakan biaya aktivitas sehari-hari yang berhubungan langsung dengan aktivitas sehari-hari meliputi biaya gaji, pemasaran dan biaya bunga serta kegiatan usaha yang berlangsung. Sedangkan pendapatan operasional merupakan pendapatan yang diterima oleh pihak bank melalui hasil dari kegiatan operasionalyang dilakukan salah satunya pendapatan dari penyaluran kredit dan kegiatan usaha bank yang benar-benar telah diterima (Prasanjaya \& Ramantha, 2013).

\section{Rerutn on Asset (ROA)}

$R O A$ adalah rasio yang menggambarkan kemampuan bank dalam menghasilkan laba, untuk meningkatkan profitabilitas perusahaan harus mampu menganalisis kerugian yang mungkin terjadi (Yudiana, 2013). rasio Return on Asset $(R O A)$ merupakan salah satu indikator utama dalam penentuan tingkat kesehatan bank. Alasan mengapa Return on Asset (ROA) dari pada Return on Equity $(R O E)$ karena Bank Indonesia mengutamakan nilai profitabilitas suatu bank yang diukur dengan asset yang dananya sebagian besar berasal dari simpanan masyarakat sehingga $R O A$ lebih mewakili dalam mengukur tingkat profitabilitas perbankan (Dendawijaya, 2008)

\section{Kerangka Konseptual}

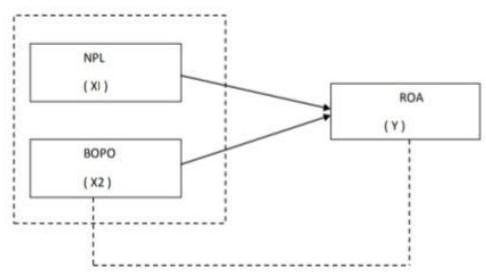

Gambar 2.1 Kerangka Konseptual Penelitian

Keterangan:

$\longrightarrow:$ Pengaruh masing-masing

$------\rightarrow$ : Pengaruh variabel secara

simultan.

\section{Uji Random Effect Model}

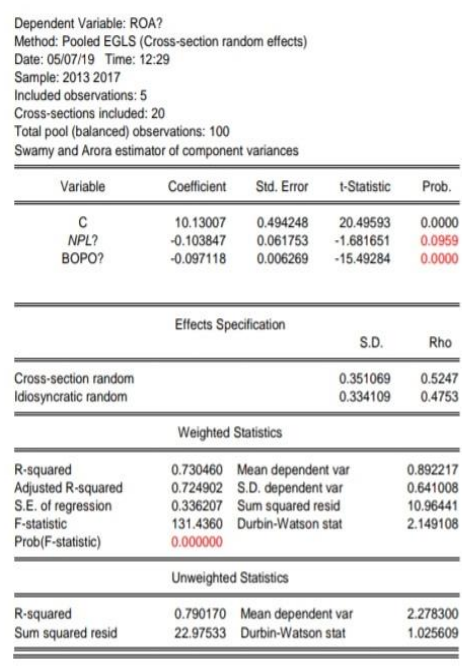

Sumber: Data diolah eviews, 2019

a. Nilai koefisien sebesar 10.13007 menunjukkan bahwa ketika nilai variabel independen dalam hal ini $N P L$ dan BOPO sama dengan nol maka nilai $R O A$ sebesar $10.13 \%$.

b. Nilai koefisien NPL sebesar 0.103846 yang apabila nilai $N P L$ mengalami kenaikan sebesar satu persen sementara variabel independen lainnya bersifat tetap maka akan menurunkan nilai $R O A$ sebesar $0.1 \%$

c. Nilai koefisien BOPO sebesar 0.097118 yang apabila BOPO mengalami kenaikan satu persen sedangkan nilai dari variabel lainnya tetap, maka akan menurunkan $R O A$ sebesar $0.09 \%$. 


\section{HASIL DAN PEMBAHASAN}

\section{Uji Hipotesis}

\section{Hipotesis Uji T( Parsial )}

\section{Hipotesis I : NPL Berpengaruh Signifikan Terhadap $R O A$}

Dengan pengambilan keputusan sebagai berikut

$\mathrm{H} 0$ : $N P L$ tidak berpengaruh signifikan terhadap $R O A$

\section{$\mathrm{H} 1$ : NPL berpengaruh signifikan terhadap ROA}

Berdasarkan hasil penelitian yang dilakukan menggunakan random effect model dapat dilihat dari nilai pada tabel probabilitas untuk NPL sebesar 0.0959 dimana lebih besar dari standar 0.05 dengan tingkat kepercayaan $95 \%$ dapat disimpulkan bahwa H0 diterima dan $\mathrm{H} 1$ ditolak yang berarti $N P L$ tidak berpengaruh signifikan terhadap $R O A$ dengan nilai koefisien regresi sebesar -0.103846. Dalam hal ini peningkatan NPL dapat menurunkan ROA sebesar $0.1 \%$. NPL memberikan efek negatif tidak signifikan terhadapa ROA. Semakin besar rasio dari $N P L$ maka akan semakin besar kredit macet yang akan ditanggung oleh perbankan di karnakan pinjaman atau kredit yang diberikan tidak dapat dikembalikan begitu juga sebaliknya.

\section{Hipotesis II : BOPO Berpengaruh Signifikan Terhadap ROA}

Dengan pengambilan keputusan sebagai berikut

H0 : BOPO tidak berpengaruh signifikan terhadap $R O A$

$\mathrm{H} 1$ : BOPO berpengaruh signifikan terhadap $R O A$

Berdasarkan hasil penelitian yang dilakukan menggunakan random effect model dilihat dari nilai pada tabel probabilitas untuk BOPO memiliki nilai sebesar 0.0000 yang dimana lebih kecil dari standar 0.05 atau $5 \%$ dengan tingkat kepercayaan $95 \%$ dapat disimpulkan bahwa $\mathrm{H} 0$ ditolak dan $\mathrm{H} 2$ diterima yang berarti BOPO berpengaruh negatif dan signifikan terhadap ROA. Dengan nilai koefisien sebesar -0.097118 yang berarti setiap peningkatan BOPO menurunkan ROA sebesar $0.09 \%$. BOPO merupakan rasio perbandingan antara beban operasional terhadap pendapatan operasional yang dimana jika semakin kecil biaya operasional yang dikeluarkan maka akan semakin besar profitabilitas yang didapatkan sehingga bank tersebut termasuk dalam kategori dapat mengefesiensikan biaya yang dikeluarkan.
Uji F ( Simultan)

\section{Hipotesis III :NPL dan BOPO Berpengaruh Terhadap ROA}

Dengan pengambilan keputusan sebagai berikut

H0 : NPL dan BOPO Tidak Berpengaruh Terhadap $R O A$

\section{H1: NPL dan BOPO BerpengaruhTerhadap ROA}

Berdasarkan hasil penelitian yang dilakukan menggunakan random effect model dapat dilihat dari nilai pada tabel $\mathrm{f}$ probabilitas untuk mengetahui pengaruh silmutan yang dimana nilai dari f probabilitas sebesar 0.0000 lebih kecil dari 0.05 yang berarti bahwa kedua variabel independen mempunyai pengaruh signifikan secara bersamasama terhadap variabel dependen.Yang berarti bahwa kedua dari variabel independen tersebut dapat memberikan profitabilitas bagi perbankan.

\section{Koefisien Determinasi $\left(\boldsymbol{R}^{2}\right)$}

Berdasarkan hasil Tabel 4.6 menunjukkan nilai R-square 0.730460 merupakan nilai simultan dari kedua variabel dan nilai adjusted $R$-square 0.724902 merupakan nilai simultan kedua variabel dengan memperhatikan standar error, dari kedua nilai tersebut sama-sama mendekati 1 dalam hal ini kedua variabel NPL dan BOPO mempunyai kemampuan serta informasi dalam menjelaskan profitabilitas atau ROA sebesar $0.73 \%$ dan $0.72 \%$ di bursa efek indonesia pada tahun 2013-2017 dan sisanya di jelaskan dan dipengaruhi oleh variabel lain yang tidak dimasukkan didalam penelitian ini.

\section{PEMBAHASAN}

1. Pengaruh NPL Terhadap ROA

Berdasarkan hasil analisis pengujian hipotesis di atas, bahwa NPL tidak berpengaruh signifikan tetapi mempunyai efek negatif terhadap ROA. Hal tersebut di karenakan dalam penelitian ini nilai dari $N P L$ masing-masing perbankan yang menjadi sampel masih dibawa 5\% yang merupakan standar yang ditetapkan dari BI, sehingga hasil menunjukkan NPL tidak berpengaruh signifikan terhadap ROA. Akan tetapi ketika nilai $N P L$ melebihi batas maksimum yang di tetapkan oleh BI maka akan memberikan pengaruh yang positif menurunkan $R O A$. Hal ini menunjukkan hasil yang sejalan dengan teori yang sudah di bahas sebelumnya oleh (Masril, 2018) mengatakan bahwa semakin tinggi tingkat NPL maka semakin buruk kualitas kredit yang menyebabkan penurunan pendapatan. Penelitian ini didukung oleh 
penelitian yang dilakukan oleh Nazir \& Mahfuzah (2018) yang menyatakan bahwa $N P L$ tidak berpengaruh signifikan terhadap $R O A$ tetapi bertentangan dengan penelitian yang dilakukan oleh Kansil et.al, dalam penelitiannya yang berjudul pengaruh risiko perbankan terhadap kinerja keuangan di dalam penelitiannya terdapat tiga variabel independen yaitu $N P L, L D R$, dan BOPO nilai dari rasio NPL dan BOPO telah melewati batas dari standar dan ketentuan yang di keluarkan oleh BI sehingga hasil menunjukkan bahwa NPL berpengaruh negatif signifikan terhadap $R O A$.

2. Pengaruh BOPO Terhadap $R O A$

Berdasarkan hasil pengujian hipotesis kedua bahwa diketahui BOPO berpengaruh negatif signifikan terhadap ROA. Hal ini sejalan dengan teori yang sudah dibahas sebelumnya oleh (Dendawijaya, 2018) yang menyatakan bahwa resiko operasional dapat menurunkan profitabilitas perusahaan, karena dalam menjalankan operasional perbankan berhati-hati dalam melakukan kegiatan menghimpun dan menyalurkan dana serta dapat mengefesiensikan biaya yang dikeluarkan untuk melakukan kegiatan operasional agar dapat meningkatkan pofitabilitas. Dalam penelitian ini nilai BOPO melebihi standar yang di tetap kan BI yaitu diatas $94 \%$. Dengan ini penelitian didukung oleh semua hasil penelitian terdahulu yang telah dibahas sebelumnya yang berarti bahwa semakin tinggi biaya yang dikeluarkan dapat membuat perbankan tidak efesien dalam mengeluarkan biaya operasional hal tersebut dapat mempengaruhi perbankan dalam mendapatkan profitabilitas.

3. Pengaruh $N P L$ dan BOPO Terhadap ROA

Melihat hasil pengujian hipotesis secara bersama-sama, bahwa kedua variabel independen berpengaruh signifikan terhadap ROA. Hasil penelitian ini didukung oleh teori yang sudah dibahas sebelum oleh (Yudiana, 2013) yang menyatakan kedua variabel independen secara bersama-sama dapat meningkatkan dan menurunkan profitabilitas perbankan. Begitu juga penelitian ini didukung oleh penelitian terdahulu yang dilakukan oleh kansil et.al (2017) menyatakan $N P L$, dan BOPO berpengaruh secara samasama. Tingginya rasio NPL dapat menurunkan pendapatan perbankan dalam mengembalikan dana yang telah diberikan kepada debitur, begitu juga dengan tingginya rasio BOPO menunjukkan tidak efesienya perbankan dalam menjalankan operasional sehingga dapat menyebabkan kerugian bagi perbankan.

\section{PENUTUP}

\section{SARAN}

Bagi peneliti atau pembaca selanjutnya, diharapkan penelitian ini dapat menjadi refrensi dan masukkan untuk menambah wawasan. Diharapkan kepada peneliti selanjutnya untuk dapat menambah jumlah variabel dan jumlah sampel dalam penelitiannnya sehingga dapat memberikan informasi baru untuk kedepannya sehingga mengetahui lebih dalam lagi penyebab NPL tidak berpengaruh signifikan terhadap $R O A$

\section{REFERENSI}

Bank Indonesia.(2011). Surat Edaran Bank Indonesia No.13/PBI/2011. Tentang Penilaian Tingkat Kesehatan Bank Umum: Jakarta.

Bank Indonesia.(2011). Peraturan Bank Indonesia No.13/24/2011. Tentang Standar Nilai Rasio BOPO: Jakarta.

Bank Indonesia.(2015). Peraturan Bank Indonesia No. 17/11/2015. Tentang Standar Nilai Rasio NPL:Jakarta.

Dendawijaya, Lukman. (2018). Manajemen Perbankan. Cetakan Ketiga. Jakarta: Penerbit Ghalia Indonesia.

Dendawijaya, Lukman. (2008). Manajemen Perbankan.Edisi 2. Bogor: Penerbit: Ghalia Indonesia.

Endraswara, Suwardi. (2011). Metodologi Penelitian Sastra.Jakarta : PT. Buku Seru.

Ismail.(2014). Akuntasi Bank Teori Dan Aplikasi Dalam Rupiah. Jakarta: Kencana Prenadamedia Group.

Ikatan Bankir Indonesia. (2015). Manjemen Risiko 1. Jakarta: Penerbit PT. Gramedia Pustaka Utama.

Kansil,Deyby, Sri Murni, Joy, Elly, Tulung. (2017). Pengaruh Risiko Perbankan Terhadap Kinerja Keuangan.Jurnal Ekonomi Dan Bisnis, Vol.5 No.1.

Kasmir.(2012). Dasar-dasar Perbankan. Jakarta:Penerbit PT Raja Crafindo Persada.

Kasmir. (2014). Bank dan lembaga keuangan lainnya. Edisi Revisi 2014 Jakarta: Raja Grafindo Persada.

Masril. (2018). Pengaruh $L D R, N P L$ Dan Harga Saham Terhadap ROA Dengan Jumlah Asset Sebagai Moderating Pada Perbankan 
Di Indonesia (Studi Kasus Pada Bank Konversional Yang Terdaftar BEI). Ejournal Adminitrasi Bisnis. Vol. 5 (4): 1229-1240.

Nazir, Ristati \& Mahfuzah, Nurul. (2018). Pengaruh Penerapan Manajemen Risiko Terhadap Kepuasan Kinerja Keuangan Bank Pembangunan Daerah Dindonesia.Universitas Malikussaleh Lhokseunawe Jurnal Visioner Vol.7, No. 1.

Prasanjaya, Yogi, A. A., \& Ramantha I. W. (2013). Analisis Pengaruh Rasio CAR, BOPO,
LDR Dan Ukuran Perusahaan Terhadap Profitabilitas Bank Yang Terdaftar di BEI. Jurnal Akuntansi Universitas Udayana. 412302-8556.

Sugiyono. (2015). Metode Penelitian Pendidikan Pendekatan Kuantitatif, Kualitatif $R \& D$. Bandung: Alfabeta.

Yudiana, Fetria Eka. (2013). Dasar - Dasar Manajemen Keuangan. Yogyakarta: Ombak. 